\title{
Preparation and Property of Mo-Doped Visible-Light Response Titaniumdioxide Photocatalyst
}

\author{
Yingying Li, ${ }^{1}$ Xianliang Song, ${ }^{1,2}$ Zhedong Wei, ${ }^{1}$ Jianguang Zhang, \\ Lijuan Qin, ${ }^{1}$ and Shengying $\mathrm{Ye}^{1}$ \\ ${ }^{1}$ College of Food Science, South China Agricultural University, Guangzhou 510642, China \\ ${ }^{2}$ Engineering Research Center of Starch and Plant Protein Processing, South China University of Technology, Ministry of Education, \\ Guangzhou 510640, China \\ Correspondence should be addressed to Xianliang Song; songxl2000@163.com
}

Received 26 May 2014; Revised 13 August 2014; Accepted 6 September 2014; Published 14 October 2014

Academic Editor: Christoph Krafft

Copyright (C) 2014 Yingying Li et al. This is an open access article distributed under the Creative Commons Attribution License, which permits unrestricted use, distribution, and reproduction in any medium, provided the original work is properly cited.

\begin{abstract}
Mo-titaniumdioxide (P25) photocatalyst with visible-light response was prepared with the ammonium molybdate for Mo source and titaniumdioxide for the raw materials by the method of dissolving and calcining. The photocatalysts' structure was characterized by XRD, XPS, and UV-Vis absorption spectrum and TEM. The photocatalytic activities of Mo-titaniumdioxide were measured by the degradation of methylene blue $(\mathrm{MB})$ under visible-light irradiation. The results showed that Mo characteristic peaks appeared at the point of $235.45 \mathrm{eV}, 234.2 \mathrm{eV}, 232.3 \mathrm{eV}$, and $231.1 \mathrm{eV}$. In Mo-titaniumdioxide crystal lattice, $\mathrm{Mo}^{6+}$ had the highest percentage (about $84.08 \%$ ), indicating that Mo element was inserted into titaniumdioxide crystal lattice and considerable amount of Mo dopant was in the 6+ valence state, which restrained the recombination of electron-hole and had the visible-light photocatalytic activity. Photocatalytic degradation study indicated that the samples prepared at calcination temperature of $500^{\circ} \mathrm{C}$ were used to degrade MB; after $3 \mathrm{~h}$, the degradation reached up to $80.67 \%$.
\end{abstract}

\section{Introduction}

In recent years, studies of photocatalytic pollutant degradation have attracted more and more researchers' attention. In many semiconductor photocatalysts, nano- $\mathrm{TiO}_{2}$ is most commonly used due to its high chemical stability, nontoxicity, and low cost, as well as high activity and good resistance to photocorrosion. However, it has been reported that the visible-light photocatalytic activity of $\mathrm{TiO}_{2}$ is not usually satisfied because of its broadband gap $(3.2 \mathrm{eV})$ which only responds to UV light $(\lambda<387 \mathrm{~nm})$, which significantly restricts the practical application of $\mathrm{TiO}_{2}$ [1-5].

In order to broaden the photoresponse range of $\mathrm{TiO}_{2}$ from ultraviolet region to visible region and improve the availability of solar energy, many methods have been used to improve the photocatalytic property of $\mathrm{TiO}_{2}$ which include metal ion doping ( $\mathrm{Cr}$, Ir, Co, etc.) [6-8], nonmetals ion doping $\left(\mathrm{Cl}, \mathrm{N}\right.$, F, etc.) $[9,10]$, semiconductor compound $\left(\mathrm{ZrO}_{2}-\right.$ $\mathrm{TiO}_{2}, \mathrm{Fe}_{2} \mathrm{O}_{3}-\mathrm{TiO}_{2}, \mathrm{SnO}_{2}-\mathrm{TiO}_{2}$, etc.) [11-13], and deposition of noble metal on the surface (Pd, $\mathrm{Au}, \mathrm{Ag}$, etc.) [14-16]. These modification methods mainly must be implemented through sol-gel method [17] and vapor deposition method [18] and so forth. Nevertheless, the visible-light responsive $\mathrm{TiO}_{2}$ obtained with the addition of modified reagents often has certain characteristics such as larger particle size and smaller surface area. All these could result in the lower photocatalytic activity. In addition, the above synthetic methods often require harsh test conditions or special equipment, so industrial production is difficult to achieve.

P25 produced by German Degussa Company consists of $80 \%$ anatase phase and 20\% rutile phase and its diameter ranges from 20 to $40 \mathrm{~nm}$, which has the large specific surface area and is easy to obtain. Although P25 has a higher photocatalytic activity under UV-irradiation, its photocatalytic activity is low under sunlight or visible-light irradiation. Therefore, we directly modify P25 in order to obtain a high visible-light responsive photocatalyst; this research is a rewarding work. At the same time, few studies have been 
reported to modify P25 so as to improve its photocatalytic activity. The study successfully prepared Mo-P25 photocatalyst with visible-light response and explored its visible-light photocatalytic activity.

\section{Experiment}

All chemicals were of analytical grade without further purification in this study. The Mo-P25 photocatalyst (hereinafter referred to as Mo-P25) was prepared with the method of dissolving and calcining. A certain amount of ammonium molybdate $\left(\left(\mathrm{NH}_{4}\right)_{6} \mathrm{Mo}_{7} \mathrm{O}_{24} \cdot 4 \mathrm{H}_{2} \mathrm{O}\right)$ and $\mathrm{P} 25$ powders for which the molar percentage ratio of Mo element to Ti element was $0.85 \%$ were added to distilled water and stirred for $4 \mathrm{~h}$. Thus, the mixed solution was transferred to the oven at $85^{\circ} \mathrm{C}$ and dried for $24 \mathrm{~h}$. The dried sample was pulverized in the agate mortar for $0.5 \mathrm{~h}$. The compounds were annealed in air ambient temperature at $300^{\circ} \mathrm{C}, 400^{\circ} \mathrm{C}, 500^{\circ} \mathrm{C}, 600^{\circ} \mathrm{C}$, and $700^{\circ} \mathrm{C}$ for $3 \mathrm{~h}$, respectively. The heating rate of all samples was $3^{\circ} \mathrm{C} / \mathrm{min}$.

The crystalline phases of the samples were determined by X-ray powder diffraction (XRD). The XRD spectra were taken at a Rigaku (Japan) D/max-IIIA X-ray diffractometer at $45 \mathrm{kV}$ and $40 \mathrm{~mA}$ with $\mathrm{Cu}-\mathrm{K} \alpha$ radiation $(\lambda=1.5406 \mathrm{~nm})$, employing a scanning rate of $0.02^{\circ} \mathrm{s}^{-1}$ in the $2 \theta$ range from $15^{\circ}$ to $85^{\circ}$. X-ray photoelectron spectroscopy (XPS) study was carried out using an ESCALAB 250 photoelectron spectrometer (Thermo Fisher Scientific) at $2.0 \times 10^{-9} \mathrm{mbar}$ with monochromatic $\mathrm{Al} \mathrm{K} \alpha$ radiation $(E=1486.6 \mathrm{eV})$. UV-vis absorption spectra were recorded on a Hitachi U3900 spectrophotometer. Transmission electron microscopy (TEM) image was collected by using a FEI Tecnai G212 microscope.

Methylene blue (MB) was used as a convenient photostable organic molecule to assay photocatalytic activities of Mo-P25. The prepared Mo-P25 (100 mg) was dispersed into an aqueous solution $(200 \mathrm{~mL})$ of methylene blue $\left(10 \mathrm{mgL}^{-1}\right)$. The suspension was sonicated for $15 \mathrm{~min}$ followed by stirring in dark for $30 \mathrm{~min}$ to ensure an adsorption-desorption equilibrium prior to irradiation. Then, the suspension was irradiated with a $85 \mathrm{~W}$ incandescent lamp while stirring. The solution of $10 \mathrm{~mL}$ was collected from the suspension after different reaction time and was immediately centrifuged at $6000 \mathrm{rpm}$ for $15 \mathrm{~min}$. The concentration of $\mathrm{MB}$ after illumination was determined spectrophotometrically at $664 \mathrm{~nm}$ by a UV-vis spectrophotometer. The photocatalytic activities of the catalysts were measured in terms of the degradation efficiency (\%) of $\mathrm{MB}$ by the following equation:

$$
\text { Degradation efficiency }(\%)=\frac{C_{0}-C}{C_{0}} * 100 \text {, }
$$

where $C_{0}$ is the initial concentration of $\mathrm{MB}$ and $C$ is the concentration of MB after visible-light irradiation.

\section{Results and Discussion}

3.1. XRD Analysis. The XRD diffraction spectra of $\mathrm{P} 25$ and Mo-P25 with different calcination temperatures are shown

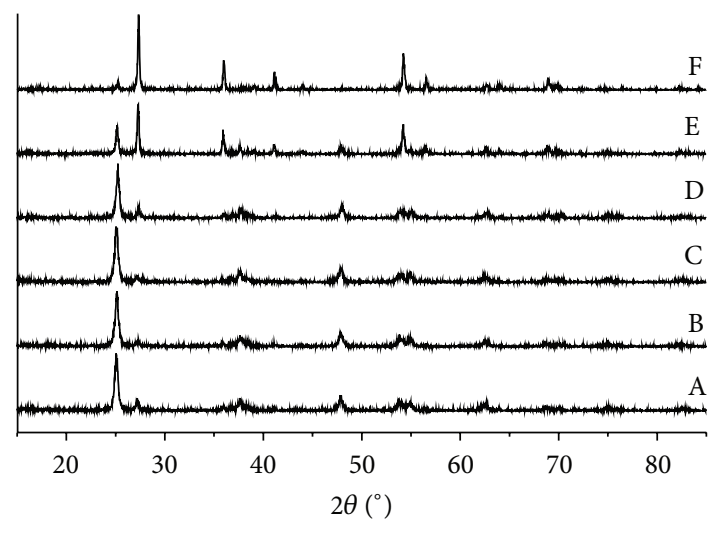

FIGURE 1: XRD spectra for samples with different calcination temperatures. A: P25, B, C, D, E, and F were Mo-P25 prepared at calcination temperature of $300^{\circ} \mathrm{C}, 400^{\circ} \mathrm{C}, 500^{\circ} \mathrm{C}, 600^{\circ} \mathrm{C}$, and $700^{\circ} \mathrm{C}$, respectively.

in Figure 1. As shown in Figure 1A, P25 which consists of $80 \%$ anatase phase and $20 \%$ rutile phase exhibited a good crystalline structure. The dominant peak at $25.3^{\circ}$ was indexed as (101) plane of anatase phase. Compared with $\mathrm{A}$, the dope of Mo made the diffraction angle of the (101) peak of P25 shift from a certain angle to a higher angle, which indicated that the addition of Mo could induce crystal lattice defects of $\mathrm{P} 25$. Figure $1 \mathrm{~B}$ and Figure $1 \mathrm{C}$ suggested that when calcination temperatures were $300^{\circ} \mathrm{C}$ and $400^{\circ} \mathrm{C}$, the diffraction peaks of rutile phase became weaker than P25, which showed that Mo could restrain the growth of rutile phase, obviously (110) plane of rutile phase. With calcination temperature increasing to $500^{\circ} \mathrm{C}$, a few of anatase phases were transformed to rutile phase initially, but not apparently. When calcination temperature reached $600^{\circ} \mathrm{C}$, the diffraction peaks of rutile phase became sharp, indicating that anatase phase was transformed to rutile phase gradually. By further increase of calcination temperature to $700^{\circ} \mathrm{C}$, anatase phase disappeared nearly. No obvious peaks of Mo could be detected; this was because the ionic radius of $\mathrm{Mo}^{6+}$ was $0.062 \mathrm{~nm}$ and that of $\mathrm{Ti}^{4+}$ was $0.068 \mathrm{~nm} ; \mathrm{Mo}^{6+}$ was incorporated into P25 crystal lattice. And the doping quantity may be so small that the XRD instruments could not detect its signal.

3.2. XPS Analysis. Figure 2 shows that a peak appearing at the range from $200 \mathrm{eV}$ to $300 \mathrm{eV}$ was Mo element characteristic peak, which fairly accorded with experimental result reported in [19], indicating that Mo element was incorporated into P25 crystal lattice successfully. The three bands which appeared at $531 \mathrm{eV}, 458.7 \mathrm{eV}$, and $284 \mathrm{eV}$ were ascribed to the $\mathrm{O}(1 \mathrm{~s}), \mathrm{Ti}(2 \mathrm{p})$, and $\mathrm{C}(1 \mathrm{~s})$, respectively, and $\mathrm{C}(1 \mathrm{~s})$ characteristic peak was caused by carbon contamination in the test system. Table 1 shows that the atomic percentage of Mo was only $0.8 \%$ in Mo-P25 samples by XPS which was corresponding with the detection results of XRD. The doping amount of Mo element was so little that it could not change the main crystal structure of P25.

Figure 3 shows that the deconvolution of $\mathrm{Mo}(3 \mathrm{~d})$ peak resulted in four peaks centered at $235.45 \mathrm{eV}, 234.2 \mathrm{eV}, 232.3 \mathrm{eV}$, 


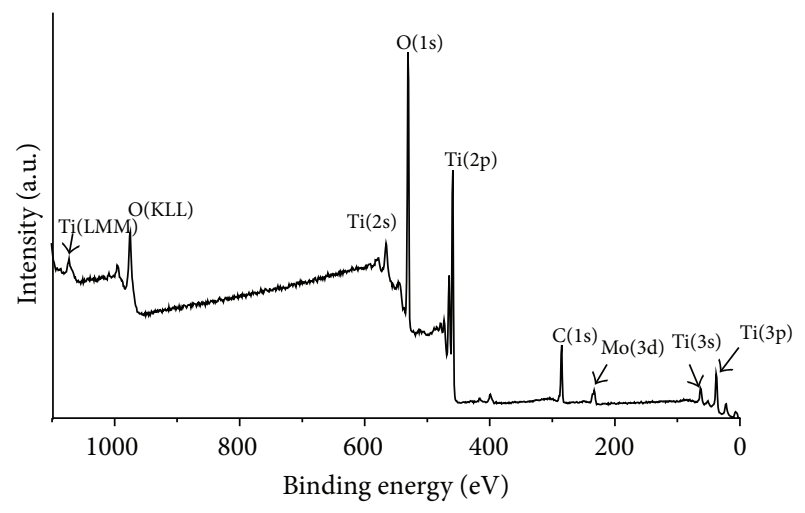

FIGURE 2: XPS spectra of Mo-P25.

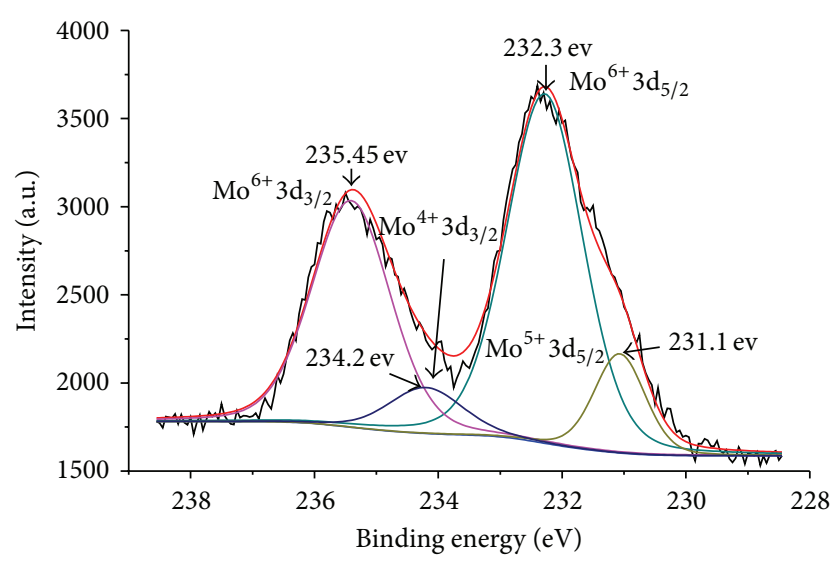

FIGURE 3: XPS spectra of Mo element.

TABLE 1: The atomic content of Mo-P25.

\begin{tabular}{lccc}
\hline Peak & Position BE (eV) & Raw area (CPS) & Atomic conc. \% \\
\hline $\mathrm{C}(1 \mathrm{~s})$ & 284.81 & 17833.21 & 25.14 \\
$\mathrm{O}(1 \mathrm{~s})$ & 530.16 & 88892.73 & 53.54 \\
$\mathrm{Ti}(2 \mathrm{p})$ & 458.92 & 96617.39 & 20.52 \\
$\mathrm{Mo}(3 \mathrm{~d})$ & 232.39 & 6363.95 & 0.8 \\
\hline
\end{tabular}

TABLE 2: The content of different Mo valence state.

\begin{tabular}{lcccc}
\hline \multicolumn{5}{c}{ Mo species analysis } \\
Name & Energy (ev) & FWHM & Area & Ti/at\% \\
\hline $\mathrm{Mo}^{6+} 3 \mathrm{~d}_{3 / 2}$ & 235.41 & 1.5 & 2250.084 & 33.73184 \\
$\mathrm{Mo}^{6+} 3 \mathrm{~d}_{5 / 2}$ & 232.28 & 1.45 & 3358.334 & 50.34603 \\
$\mathrm{Mo}^{5+} 3 \mathrm{~d}_{5 / 2}$ & 231.07 & 0.97 & 635.9796 & 9.534206 \\
$\mathrm{Mo}^{5+} 3 \mathrm{~d}_{3 / 2}$ & 234.2 & 1.4 & 426.1064 & 6.387919 \\
\hline
\end{tabular}

and $231.1 \mathrm{eV}$. According to the PEAKFIT resolved peaks and literatures [20], the peaks were identified as $\mathrm{Mo}^{6+}$ and $\mathrm{Mo}^{5+}$. Every valent Mo content was obtained by dealing with detection results which is listed in Table 2 . As shown in Table $2, \mathrm{Mo}^{6+}$ had the highest percentage (more than $80 \%$ ), indicating that Mo element was incorporated into P25 crystal lattice and considerable amount of Mo was in the $6+$ valence state.

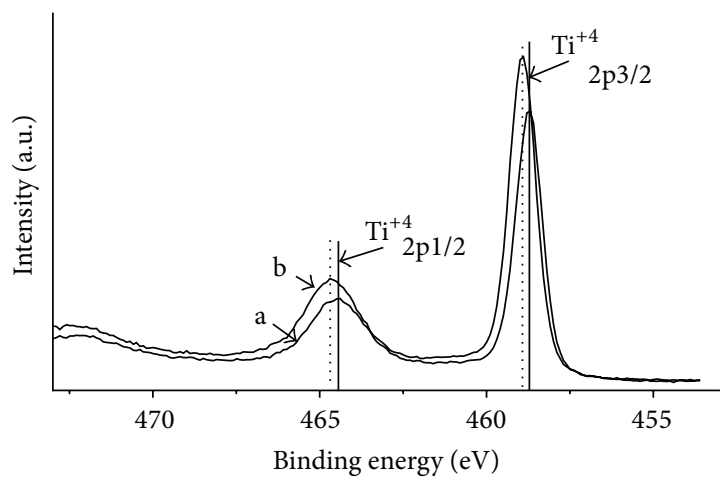

FIgURE 4: XPS spectra of Ti element of P25 and Mo-P25, respectively. a: Ti element of P25. b: Ti element of Mo-P25.

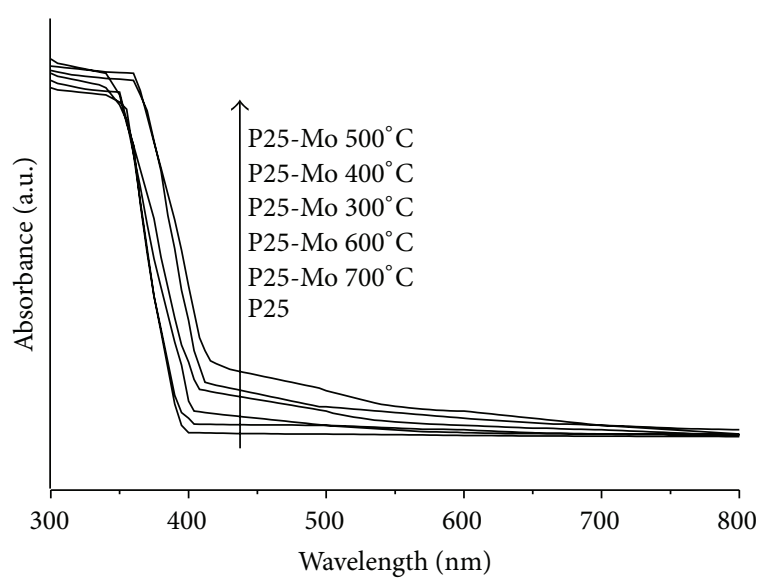

Figure 5: UV-vis spectra for P25 and Mo-P25 calcined at different temperatures.

XPS spectra of Ti element of P25 and Mo-P25 were shown in Figure 4. As shown in Figure 4a, the binding energy of Ti2p1/2 was $464.5 \mathrm{eV}$ which was higher than that $(458.7 \mathrm{eV})$ for Ti2p3/2; peak patterns of Ti2p1/2 and Ti2p3/2 presented a symmetric distribution, so the peaks of $\mathrm{Ti}$ were identified as $\mathrm{Ti}^{4+}$ characteristic peak. As shown in Figure 4b, compared with Figure $4 \mathrm{a}$, the binding energy of Ti peak was shifted to higher binding energy; this was because Mo doped into P25 crystal lattice had higher chemical valence state than $\mathrm{Ti}$ of P25 and seized the oxygen atom of P25 crystal lattice to form $\mathrm{Mo}_{x} \mathrm{O}_{y}$, which led to the decrease of Ti electron density and the increase of Ti binding energy.

3.3. UV-Vis Analysis. Figure 5 shows that $\mathrm{P} 25$ almost did not have photoabsorption in the visible region. However, MoP25 prepared at different calcination temperatures had strong photoabsorption accompanied with red shift phenomenon; this was due to the dope of Mo which caused lattice defects of P25, along with the distortion of crystal lattice. All these contributed to producing more oxidation centers in $\mathrm{Ti}^{3+}$ and greatly decreased the recombination of electron and hole which made light response region shift to visiblelight region and improved the visible-light photocatalytic 


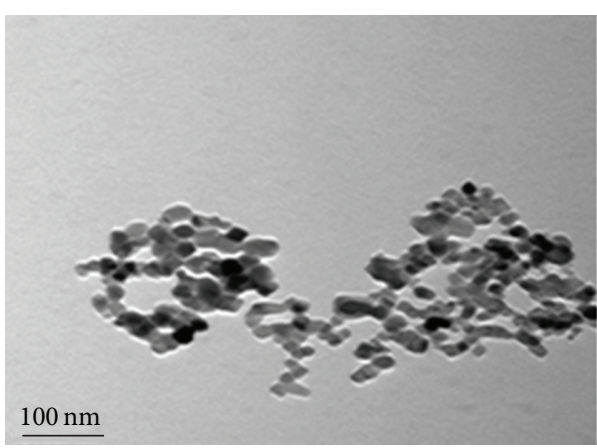

(a) TEM image of P25

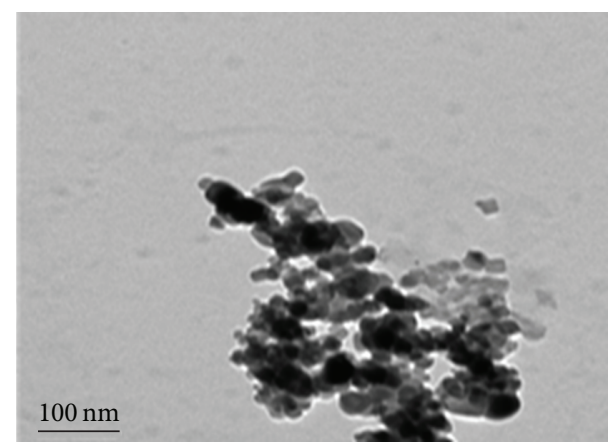

(b) TEM image of Mo-P25

Figure 6: TEM images of P25 and Mo-P25.

activity. However, different calcination temperature had an obvious influence on the visible photoabsorption of Mo$\mathrm{P} 25$. When calcination temperature was $500^{\circ} \mathrm{C}$, a few of anatase phases were transformed to rutile phase initially and mixed crystal effect was generated under the giant amount of anatase phase and the small amount of rutile phase which had evident positive effect on the improvement of visible photoabsorption. When calcination temperature reached $700^{\circ} \mathrm{C}$, the photoabsorption of Mo-p25 decreased rapidly in visible-light region. This was because that anatase phase almost disappeared, and rutile phase was transformed from anatase phase which was mostly inactive. When calcination temperature was $300^{\circ} \mathrm{C}$, the visible photoabsorption and red shift phenomenon of Mo-P25 were not evident; this was because calcination temperature was too low and Mo element was hardly incorporated into P25 crystal lattice.

3.4. TEM Analysis. Figure 6(a) shows that $\mathrm{P} 25$ particles were uniform in size with the range dimension of $20-40 \mathrm{~nm}$ by means of ultrasonic dispersion. Compared with Figure 6(a), Figure 6(b) shows that Mo-P25 nanoparticles were agglomerated easily in aqueous solution and were irregular in shape; the reason was that $\mathrm{Mo}^{6+}$ substituted $\mathrm{Ti}^{4+}$ in P25 crystal lattice and this substitution caused lattice defects.

3.5. Photocatalytic Activity Test. Figure 7 shows that the photocatalytic activities of Mo-P25 and P25 with different calcination temperatures were evaluated under visible-light irradiation. As shown in Figure 7, the visible photocatalytic activity of P25 was very low whose degradation efficiency of $\mathrm{MB}$ was $1.58 \%$. When calcination temperature was $500^{\circ} \mathrm{C}$, Mo-P25 presented the best photocatalytic activity, and the degradation efficiency of $\mathrm{MB}$ reached $80.67 \%$. With calcination temperature continuing to increase, the photocatalytic activity of Mo-P25 dropped obviously. When calcination temperature was up to $700^{\circ} \mathrm{C}$, the degradation efficiency of $\mathrm{MB}$ was lowest, which was only $1.36 \%$. All these indicated that calcination temperature had a significant effect on the photocatalytic activity of Mo-P25. When calcination temperature was lower, heat energy hardly made P25 crystal phase transform and never let Mo be incorporated into P25 crystal lattice. However, when calcination temperature was higher,

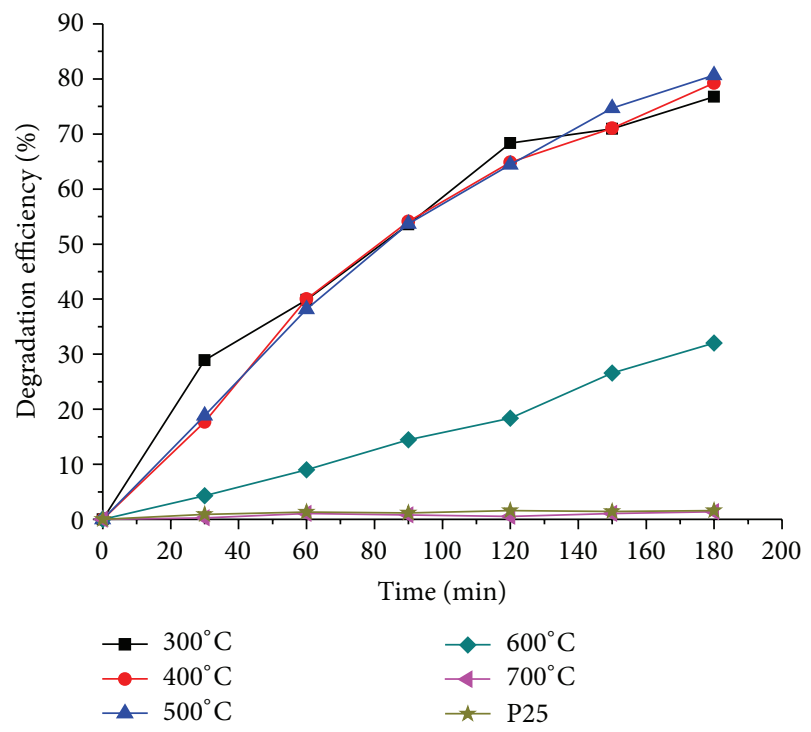

Figure 7: Photocatalytic activity of Mo-P25 and P25 with different calcination temperatures.

enough heat energy made almost all anatase phase transform to rutile phase, which would reduce the photocatalytic activity. Therefore, with calcination temperature increasing, the photocatalytic activity of Mo-P25 presented the downward trend after the first rise.

\section{Conclusion}

Mo-P25 photocatalysts were prepared by the method of dissolving and calcining. The photocatalytic activities of MoP25 samples prepared at different calcination temperature were measured by measuring the degradation of methylene blue. The results showed that calcination temperature was an important factor affecting the photocatalytic activity. When calcination temperature was $500^{\circ} \mathrm{C}, \mathrm{Mo}-\mathrm{P} 25$ photocatalyst presented the best photocatalytic activity and the degradation efficiency of $\mathrm{MB}$ reached up to $80.67 \%$. The structure characterization of Mo-P25 prepared at different calcination temperature indicated that when calcination temperature was 
$500^{\circ} \mathrm{C}$, a few of anatase phases were transformed to rutile phase initially. With calcination temperature increasing to $700^{\circ} \mathrm{C}$, almost all anatase phase was transformed to rutile phase. By calcining $\mathrm{Ti}^{4+}$ was substituted for $\mathrm{Mo}^{6+}$ into P25 crystal lattice. The visible photoabsorption was improved under the action of Mo dopant. The red shift of the absorption spectrum took place evidently. All these were contributed to the increase of the photocatalytic activities of Mo-P25.

\section{Conflict of Interests}

The authors declare that there is no conflict of interests regarding the publication of this paper.

\section{Acknowledgments}

This research was supported by the National Nature Science Foundation of China (31371855), Science and Technology Plan Project of Guangzhou (2014J4100150), and Engineering Research Center of Starch and Plant Protein Processing from Ministry of Education (201106).

\section{References}

[1] S. H. Lim, C. Ferraris, M. Schreyer, K. Shih, J. O. Leckie, and T. J. White, "The influence of cobalt doping on photocatalytic nanotitania: crystal chemistry and amorphicity," Journal of Solid State Chemistry, vol. 180, no. 10, pp. 2905-2915, 2007.

[2] K. Nagaveni, G. Sivalingam, M. S. Hegde, and G. Madras, "Solar photocatalytic degradation of dyes: high activity of combustion synthesized nano $\mathrm{TiO}_{2}$," Applied Catalysis B: Environmental, vol. 48, no. 2, pp. 83-93, 2004.

[3] O. Carp, C. L. Huisman, and A. Reller, "Photoinduced reactivity of titanium dioxide," Progress in Solid State Chemistry, vol. 32, no. 1-2, pp. 33-177, 2004.

[4] M. Hamadanian, A. Reisi-Vanani, and A. Majedi, "Synthesis, characterization and effect of calcination temperature on phase transformation and photocatalytic activity of $\mathrm{Cu}, \mathrm{S}$-codoped $\mathrm{TiO}_{2}$ nanoparticles," Applied Surface Science, vol. 256, no. 6, pp. 1837-1844, 2010.

[5] X. Cheng, X. Yu, and Z. Xing, "One-step synthesis of visible active CNS-tridoped $\mathrm{TiO}_{2}$ photocatalyst from biomolecule cystine," Applied Surface Science, vol. 258, no. 19, pp. 7644-7650, 2012.

[6] S. J. Zhang, "Synergistic effects of C-Cr codoping in $\mathrm{TiO}_{2}$ and enhanced sonocatalytic activity under ultrasonic irradiation," Ultrasonics Sonochemistry, vol. 19, no. 4, pp. 767-771, 2012.

[7] P. Chen, J. Lu, G. Xie, L. Zhu, and M. Luo, "Characterizations of $\mathrm{Ir} / \mathrm{TiO}_{2}$ catalysts with different Ir contents for selective hydrogenation of crotonaldehyde," Reaction Kinetics, Mechanisms and Catalysis, vol. 106, no. 2, pp. 419-434, 2012.

[8] S.-Y. Liu, W.-H. Tang, Q.-G. Feng, J.-Z. Li, and J.-H. Sun, "Synthesis of N, Fe Co-doped $\mathrm{TiO}_{2}$ nanomaterials via solid state reaction and their photodegradation of quinoline irradiated under visible light," Journal of Inorganic Materials, vol. 25, no. 9, pp. 921-927, 2010.

[9] X.-K. Wang, C. Wang, W.-Q. Jiang, W.-L. Guo, and J.-G. Wang, "Sonochemical synthesis and characterization of Cl-doped $\mathrm{TiO}_{2}$ and its application in the photodegradation of phthalate ester under visible light irradiation," Chemical Engineering Journal, vol. 189-190, pp. 288-294, 2012.

[10] W. Wang, C. H. Lu, Y. R. Ni, M. X. Su, W. J. Huang, and Z. Z. Xu, "Preparation and characterization of visible-light-driven N-FTa tri-doped $\mathrm{TiO}_{2}$ photocatalysts," Applied Surface Science, vol. 258, no. 22, pp. 8696-8703, 2012.

[11] A. Naumenko, I. Gnatiuk, N. Smirnova, and A. Eremenko, "Characterization of sol-gel derived $\mathrm{TiO}_{2} / \mathrm{ZrO}_{2}$ films and powders by Raman spectroscopy," Thin Solid Films, vol. 520, no. 14, pp. 4541-4546, 2012.

[12] Q. Sun, W. Leng, Z. Li, and Y. Xu, "Effect of surface $\mathrm{Fe}_{2} \mathrm{O}_{3}$ clusters on the photocatalytic activity of $\mathrm{TiO}_{2}$ for phenol degradation in water," Journal of Hazardous Materials, vol. 229230, pp. 224-232, 2012.

[13] B. C. Yadav, N. Verma, and S. Singh, "Nanocrystalline $\mathrm{SnO}_{2}$ $\mathrm{TiO}_{2}$ thin film deposited on base of equilateral prism as an optoelectronic humidity sensor," Optics and Laser Technology, vol. 44, no. 6, pp. 1681-1688, 2012.

[14] A. Yildiz, D. Crisan, N. Dragan, N. Iftimie, D. Florea, and D. Mardare, "Effect of formaldehyde gas adsorption on the electrical conductivity of $\mathrm{Pd}$-doped $\mathrm{TiO}_{2}$ thin films," Journal of Materials Science: Materials in Electronics, vol. 22, no. 9, pp. 1420-1425, 2011.

[15] T. Nogawa, T. Isobe, S. Matsushita, and A. Nakajima, "Preparation and visible-light photocatalytic activity of $\mathrm{Au}$ - and $\mathrm{Cu}-$ modified $\mathrm{TiO}_{2}$ powders," Materials Letters, vol. 82, pp. 174-177, 2012.

[16] V. Mirkhani, S. Tangestaninejad, M. Moghadam, M. H. Habibi, and A. Rostami Vartooni, "Photodegradation of aromatic amines by $\mathrm{Ag}-\mathrm{TiO}_{2}$ photocatalyst," Journal of the Iranian Chemical Society, vol. 6, no. 4, pp. 800-807, 2009.

[17] X. Zhang, H. Yang, F. Zhang, and K.-Y. Chan, "Preparation and characterization of $\mathrm{Pt}-\mathrm{TiO}_{2}-\mathrm{SiO}_{2}$ mesoporous materials and visible-light photocatalytic performance," Materials Letters, vol. 61, no. 11-12, pp. 2231-2234, 2007.

[18] X.-X. Wang, X. Chen, H.-B. Xu, and X.-Z. Fu, "Advance in modification method of zeolite molecular sieve surface," Chinese Journal of Inorganic Chemistry, vol. 18, no. 6, pp. 541549, 2002.

[19] Y. Shen, T. Xiong, H. Du, H. Jin, J. Shang, and K. Yang, "Phosphorous, nitrogen, and molybdenum ternary co-doped $\mathrm{TiO}_{2}$ : preparation and photocatalytic activities under visible light," Journal of Sol-Gel Science and Technology, vol. 50, no. 1, pp. 98-102, 2009.

[20] O. Y. Khyzhun, T. Strunskus, and Y. M. Solonin, "XES, XPS and NEXAFS studies of the electronic structure of cubic $\mathrm{MoO}_{1.9}$ and $\mathrm{H}_{1.63} \mathrm{MoO}_{3}$ thick films," Journal of Alloys and Compounds, vol. 366, no. 1-2, pp. 54-60, 2004. 

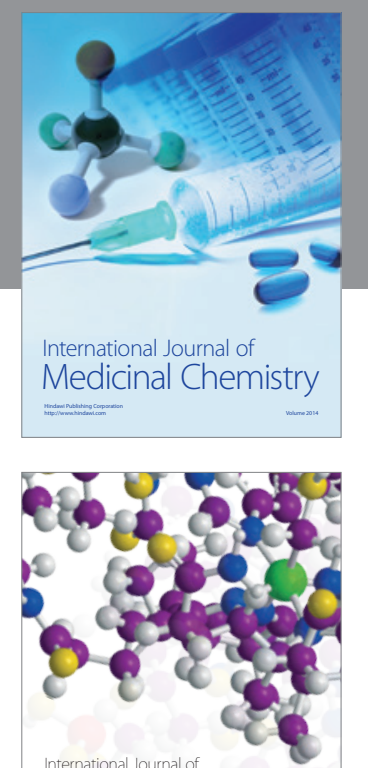

\section{Carbohydrate} Chemistry

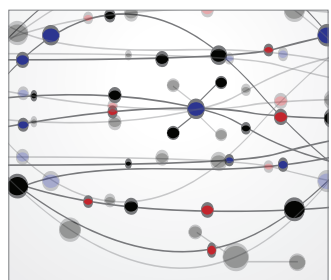

The Scientific World Journal
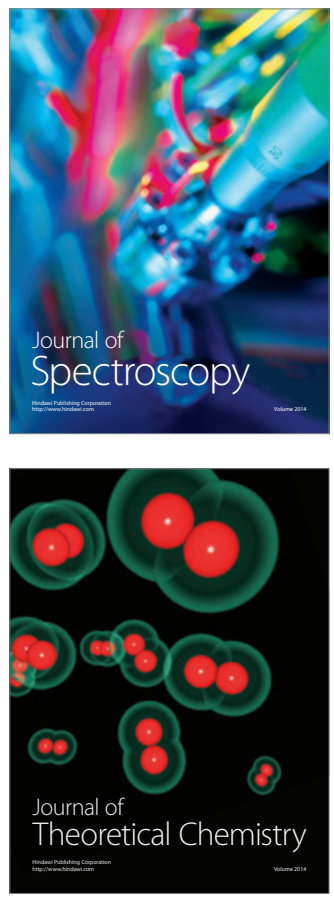
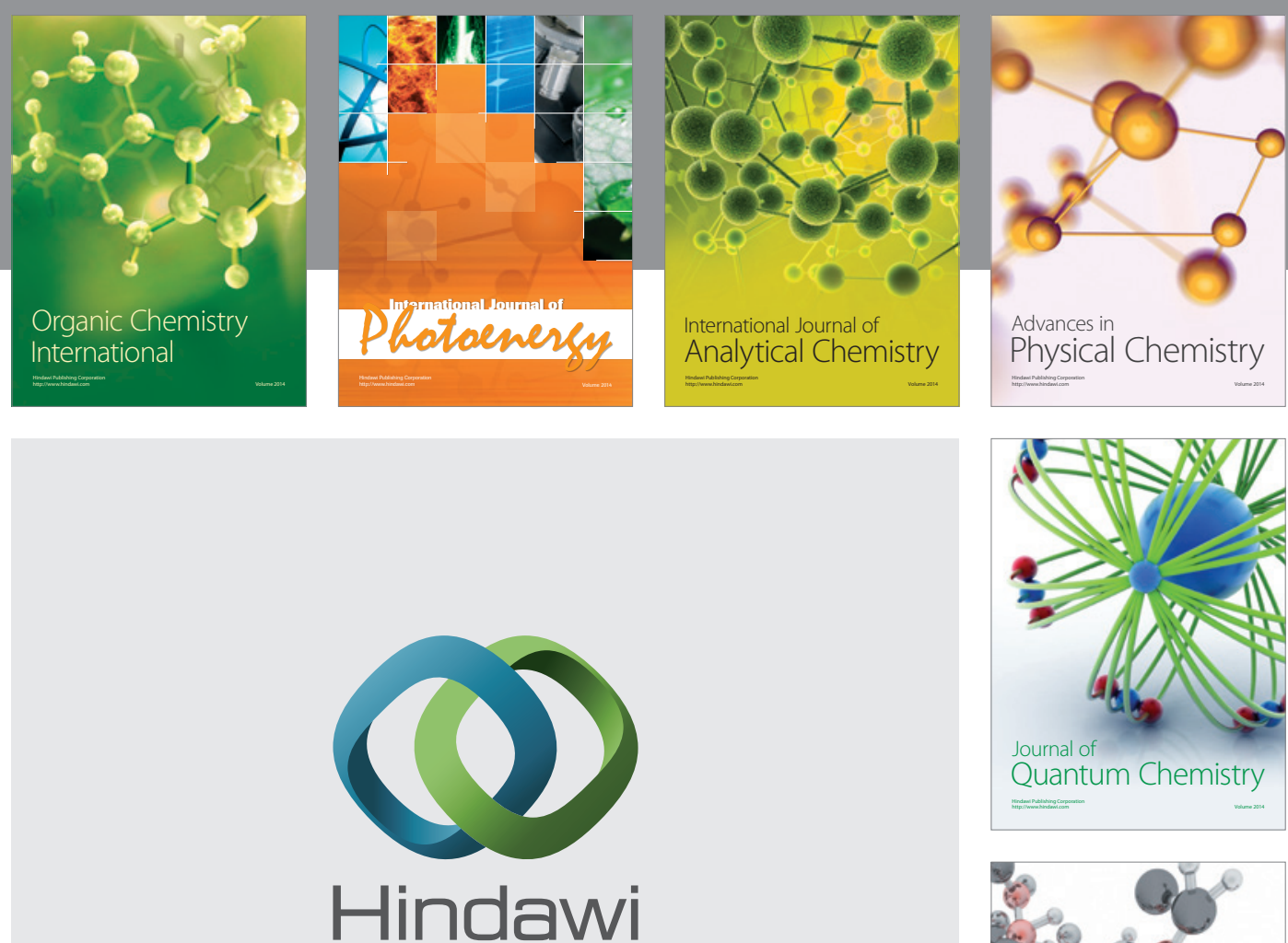

Submit your manuscripts at

http://www.hindawi.com

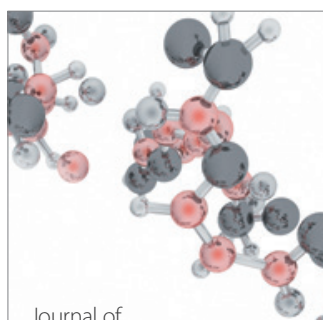

Analytical Methods

in Chemistry

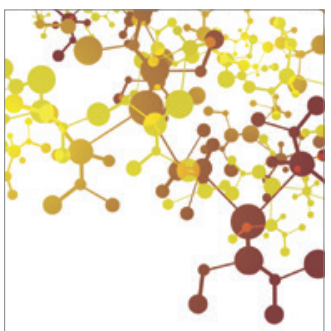

Journal of

Applied Chemistry

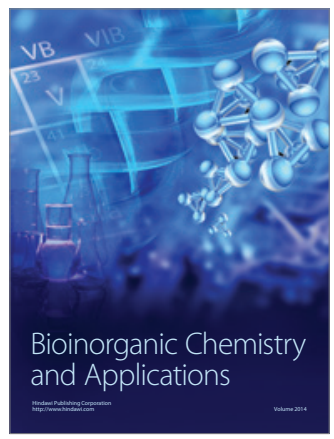

Inorganic Chemistry
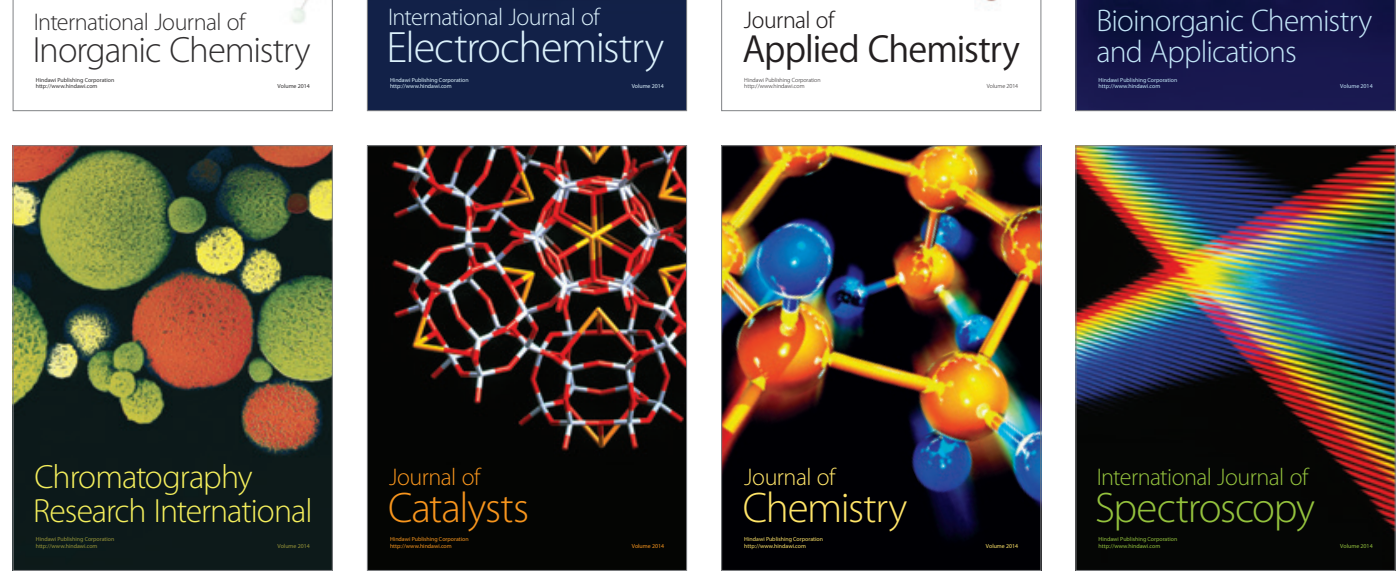